\title{
ESTRATÉGIAS PARA O ENSINO DA COVID-19 UTILIZANDO APLICATIVOS DE HISTÓRIAS EM QUADRINHOS
}

\author{
STRATEGIES FOR TEACHING COVID-19 USING COMIC BOOKS APPS
}

ESTRATEGIAS PARA ENSEÑAR LA COVID-19 POR MEDIO DE APPS DE HISTORIETAS

\begin{abstract}
Douglas Carvalho Amorim
Doutorando em Educação (UFAL). Mestre em Educação (UFAL), Maceió, AL, Brasil. Idealizador e dono do canal no Youtube "Biologia em Série", com ênfase em aulas de Biologia voltadas para o exame nacional do ensino médio (ENEM).

ORCID: https://orcid.org/0000-0001-6114-1286

E-mail: biotics.edu@gmail.com

\section{Cleide Jane de Sá Araújo Costa}

Doutora em Educação (Université de Provence Aix-Marseille I) e em Linguística (UFAL), Mestre em Psicologia (Université de Provence Aix-Marseille I). Professor Associado I do Centro de Educação da Universidade Federal de Alagoas, atuando no Programa Modelagem Computacional do Conhecimento (IC) e Programa de Pós-Graduação em Educação Brasileira, na linha de pesquisa Tecnologias da Informação e

Comunicação na Educação (PPGE).

ORCID: https://orcid.org/0000-0002-2152-0465

E-mail: cleidejanesa@gmail.com
\end{abstract}

\section{RESUMO}

Em um contexto de mudanças rápidas, trazidas pela doença Covid-19, aulas emergenciais passaram a ser realizadas por professores de forma online. Na área da Educação, possuímos meios alternativos para ensinar e aprender. Dessa forma, as histórias em quadrinhos ganharam a sala de aula, ao longo do tempo. Neste sentido, a indagação que norteou este estudo foi: como, de acordo com as percepções de professores de Biologia, estratégias pedagógicas de ensino sobre a Covid-19 podem ser mediadas com o uso de aplicativos de criação de HQs, durante as aulas remotas e após a pandemia? A hipótese que sustentou o trabalho foi a de que os professores de Biologia conseguem, sim, conceber essas estratégias de ensino. A abordagem do estudo foi qualitativa com um delineamento exploratório. Participaram da pesquisa cinco professores de Biologia. Os dados foram coletados por meio de entrevistas semiestruturadas e analisados com a técnica Análise de Conteúdo, com o auxílio do software Atlas $t i{ }^{\circledR}$. Como principais achados, o estudo revelou que os professores estabelecem essas estratégias de ensino a partir de suas vivências com HQs durante a infância, embora não conheçam, em sua maioria, aplicativos que façam a mediação com esses métodos. Conclui-se, também, que aplicativos do Google Play — voltados para a criação de HQs — podem contribuir para o ensino emergencial e no âmbito da pós-pandemia, através do ensino híbrido.

Palavras-chave: Histórias em quadrinhos; Ensino de Biologia; Ensino remoto emergencial; Covid-19; Ensino híbrido.

\section{ABSTRACT}

In a context of rapid changes brought about by Covid-19 disease, emergency classes began to be held by online teachers. In the area of Education, we have alternative means to teach and learn.The comics, thus, gained the classroom scenery over time. In this sense, the question that guided this study was: how, according to the perceptions of Biology teachers, pedagogical strategies of teaching about Covid-19 can be mediated with the use of apps for the creation of comic books, during remote classes and after the pandemic? 
The hypothesis that supported the work was that Biology teachers can, yes, conceive these teaching strategies. The approach of the study was qualitative with an exploratory design. Five Biology teachers participated in the research. Data were collected through semi-structured interviews and analyzed with the content analysis technique, with the help of Atlas ti $7^{\circledR}$. As main findings, the study revealed that teachers can establish these teaching strategies based on their experiences with comic books during childhood, although they do not know, for the most part, apps that mediate with these methods. It is also concluded that Google Play apps - aimed at creating comic books - can contribute to emergency education and also in the post-pandemic scope, through hybrid teaching.

Keywords: Comics. Biology teaching; Emergency remote education; Covid-19; Hybrid teaching.

\section{RESUMEN}

En un contexto de cambios rápidos provocados por la enfermedad Covid-19, los maestros comenzaron a impartir clases de emergencia en forma online. En el área de la Educación, tenemos a nuestra disposición medios alternativos para enseñar y aprender. De esa manera, con el tiempo, las historietas han ido ganando gradualmente el escenario del aula. En este contexto, la pregunta que orientó este estudio fue: ¿cómo, en la percepción de los profesores de Biología, posibles estrategias pedagógicas de enseñanza sobre Covid-19 pueden mediarse con el uso de aplicativos de creación de $\mathrm{HQ}$ en el contexto actual de clases remotas y también después de la pandemia? La hipótesis que apoyó el trabajo fue que los profesores de Biología pueden efectivamente idear esas estrategias. El enfoque del estudio fue cualitativo con diseño exploratorio. Participaron de la investigación cinco profesores de Biología. Los datos se recopilaron mediante entrevistas semiestructuradas y se analizaron utilizando la técnica de Análisis de Contenido, con la ayuda del software Atlas ti $7^{\circledR}$. Como hallazgos principales, el estudio reveló que los docentes pueden concebir estrategias de enseñanza a partir de sus experiencias con las historietas durante la infancia, aunque muchos no conozcan aplicativos que permitan hacer la mediación con esos métodos. Se concluye, también, que los aplicativos de Google Play - destinados a la creación de $\mathrm{HQ}$ - pueden contribuir para la educación de emergencia y también en la postpandémica, por medio de una enseñanza híbrida.

Palabras-clave: Cómics; Enseñanza de Biología; Educación remota de emergencia; Covid-19. Enseñanza híbrida.

\section{INTRODUÇÃO}

Devido ao novo coronavírus (Sars-CoV-2), causador da doença Covid-19, mudanças no cenário educacional foram tomadas, uma vez que, segundo a Organização das Nações Unidas para a Educação, Ciência e Cultura (UNESCO) ${ }^{1}$, 776 milhões de estudantes no mundo ficaram sem aulas presenciais nas instituições de ensino. Segundo a Organização Mundial da Saúde (OMS), este isolamento foi promovido porque o vírus pode ser transmitido entre os seres humanos.

Este cenário afetou os processos de ensino e aprendizagem que passaram a ser realizados por meio de aulas remotas emergenciais, promovidas pelas chamadas lives (ou 
gravações ao vivo), no mesmo horário em que ocorreriam no contexto presencial (ARRUDA, 2020). Essas aulas também podem ser gravadas para uso de estudantes que tenham problemas de conexão à internet e assistidas posteriormente por diferentes plataformas, como Google Meet, Zoom, Google Classroom de forma assíncrona (MOREIRA et al., 2020). Contudo, o modelo de lives reproduz o modelo de transmissão do conhecimento no contexto de aulas presenciais (ARRUDA, 2020), através de caminhos alternativos promovam interações entre os estudantes (TARDIF, 2014). A criação de histórias em quadrinhos (HQs), no contexto digital, pode representar um caminho promissor ao processo de ensino e aprendizagem (MOTTA; CORREIA, 2013). A relação entre HQs e Educação nem sempre foi aceita por parte dos professores e o percurso para ganhar o cenário acadêmico foi processual; entretanto, atualmente o uso de HQs é fundamentado em diferentes discussões na área (SANTOS; VERGUEIRO, 2012; VERGUEIRO; RAMOS, 2009; VERGUEIRO, 2014) e de modo específico, na educação científica (TAVARES JÚNIOR, 2015).

Ao realizarmos um recorte específico para a área da Biologia ${ }^{2}$, constatamos o interesse de produção acadêmica, ao articular HQs e o ensino da disciplina (MEHES E MAISTRO, 2012; SANTOS et al.,2012; SILVA; COSTA, 2015; TAVERES JÚNIOR, 2015; TOLEDO et al., 2016); entretanto, ainda existe uma lacuna de trabalhos que relacionem o uso de aplicativos para mediar estratégias de ensino, a partir da criação de HQs. Para o contexto atual de pandemia, ao realizarmos uma busca avançada no Portal de Periódicos da Coordenação de Aperfeiçoamento de Pessoal de Nível Superior (CAPES) e no Google Acadêmico, constatamos a ausência de estudos que relacionassem as aulas remotas emergenciais com uso de aplicativos voltados para a produção de HQs. Neste sentido, este estudo é justificado por preencher essa lacuna inicial, possibilitando a reflexão em torno de possíveis caminhos para o uso de aplicativos para o cenário atual de pandemia e póspandemia na área de Biologia.

Dentro deste contexto, a pergunta que norteou este trabalho foi: como, a partir das percepções de professores de Biologia, possíveis estratégias pedagógicas de ensino sobre Covid-19 podem ser mediadas, a partir do uso de aplicativos de criação de HQs, no contexto

\footnotetext{
${ }^{2} \mathrm{O}$ interesse do recorte se deu porque o autor do estudo possui formação inicial em Ciências Biológicas, o que facilita na análise dos dados apresentados, confrontando-os com seus conhecimentos prévios na área do conhecimento que o autor possui.
} 
atual de aulas remotas emergenciais e após a pandemia Covid-19? A hipótese que norteou o estudo foi: os professores de Biologia, deste estudo, conseguem conceber estratégias de ensino sobre Covid-19 mediadas por aplicativos de criação de HQs - a partir das aulas remotas atuais e em um contexto de pós-pandemia.

O objetivo geral do estudo foi investigar os possíveis caminhos estratégicos para o ensino da doença Covid-19, no contexto das aulas remotas emergenciais em vigor e após o término da pandemia. Para alcançá-lo, caminhos específicos foram delineados, a saber: (1) identificar as percepções dos professores de Biologia em torno das possibilidades estratégicas de ensino, mediadas por aplicativos de criação de HQs; (2) analisar os aplicativos existentes no Google Play que apresentem os pré-requisitos mínimos para a realização de possíveis intervenções nas aulas remotas dos professores de Biologia. Essas intervenções ocorreriam durante e após o término da pandemia, considerando os achados iniciais nas entrevistas dos sujeitos do estudo.

A partir destes pressupostos, na próxima seção discutiremos a relação entre $\mathrm{HQ}$ s e Educação, os desafios encontrados e os caminhos a serem considerados quando pensamos no ensino mediado por estes artefatos culturais. Em seguida, analisaremos como o campo específico da Biologia vem articulando, ao longo do tempo, a relação entre ensino e HQs. Logo após, analisaremos como no contexto atual de pandemia, como ocorre a relação entre HQs e o ensino emergencial e como essa relação pode enriquecer o ensino após o término da pandemia, em um contexto híbrido. Por último, delinearemos os percursos metodológicos do estudo, a partida da pesquisa qualitativa com delineamento exploratório, chegando aos resultados do estudo na última seção.

\section{Histórias em quadrinhos e Educação: do preconceito às iniciativas de ensino}

As histórias em quadrinhos (HQs) acompanham a evolução da espécie humana e as primeiras representações são assinaladas em pinturas rupestres em que a comunicação é estabelecida por meio de símbolos. Esses símbolos tentavam transmitir, por exemplo, o sucesso de uma caça por meio de narrativa (VERGUEIRO, 2014). O autor ainda evidencia como as crianças, em nosso contexto cultural atual, ainda representam seus pais por meio de desenhos e que isto pode ter finalidade pedagógica quando analisamos o processo de 
evolução das HQs ao longo do tempo; contudo, esse quadro nem sempre foi assim, uma vez que resistências para seu uso em espaços educativos foram evidenciadas.

Segundo Postema (2018), os quadrinhos ou HQs podem ser definidos como uma forma de arte e de narrativa em que um número de elementos, em parte pictóricos e em parte textuais, trabalham em conjunto para criar um resultado único. Os elementos pictóricos são relacionados às imagens, ou cartoons, molduras ou quadros que as compõem: os textuais, os recordatórios, balões de falas e as próprias palavras. Ainda segundo Postema (2018), as HQs existem de diferentes formas e gêneros, estruturados em sequências de imagens, com molduras ou não, associadas ao texto de algum modo, a exemplo das revistas em quadrinhos da Disney.

Ainda há muito preconceito em relação às HQs e processos de ensino por parte de adultos (pais e professores), que apresentam ceticismo para a contribuição delas para o aprimoramento cultural e moral de jovens leitores, supondo que as páginas mais coloridas das HQs pudessem afastá-los de leituras mais profundas, sérias, promovendo assim a restrição delas nas escolas por muito tempo (VERGUEIRO, 2014). Esta associação das HQs ao ceticismo adulto em relação ao seu valor educativo pode estar relacionada ao fato de que o termo remete ao início do século XX em que pessoas buscavam as chamadas FunnyPages em seus jornais e, para leitores amadores, existia uma associação direta entre HQs com brincadeiras ou à infância (POESTEMA, 2018).Contundo, a autora esclarece que existem gêneros voltados ao público adulto, como underground comix ou graphic novels e que os quadrinhos jornalísticos ou autobiográficos são geralmente os engraçados.

No contexto brasileiro e underground, com temáticas mais adultas, envolvendo política, problemas sociais e outros assuntos, Silva e Costa (2015) citam, o Níquel Náusea criado em 1985 e com publicações diárias no jornal Folha de São Paulo pelo cartunista Fernando Gonsales e equipe. O Níquel Náusea traz em seu conteúdo seres vivos, demonstrando como alguns processos biológicos se dão na natureza, como a evolução biológica - sendo útil para o ensino de Biologia de forma reflexiva e crítica.

No cenário do ensino, Vergueiro e Ramos (2009) afirmam que a entrada do século XXI representou um novo olhar em torno das HQs, consideradas formas alternativas de entretenimento e transmissão do saber para além do público infantil, voltando-se para diferentes faixas etárias. Ainda segundo os autores, houve um tempo em que levar HQs para a sala de aula era motivo de repreensão por parte dos professores, que as 
consideravam como leituras de lazer, demonstrando superficialidade nos conteúdos, gerando, assim, "preguiça mental” nos estudantes, afastando-os da "boa leitura". Atualmente, as HQs são objetos de investigação científica no Brasil, resultado da influência cultural de diferentes países do mundo (VERGUEIRO, 2017); dessa forma, as HQs ganharam espaço na prática de ensino de alguns professores mais “ousados" (SANTOS; VERGUEIRO, 2012), bem como nos livros didáticos (TOLEDO et al., 2016).

Segundo Santos e Vergueiro (2012), ter álbuns ou revistas em HQs nas bibliotecas das escolas não significa que os professores irão utilizá-las corretamente em suas aulas, sendo necessárias reflexões sobre metodologias que sejam fundamentadas em: 1) a faixa etária a que são destinadas; 2 ) utilização crítica das HQs que não foram criadas para fins educativos, mas que podem ser adaptadas pelo professor para esta finalidade; 3) leitura e conhecimento do professor sobre a linguagem dos quadrinhos, indo além da leitura textual, mas envolvendo textos com imagens e 4) a extensão: uso de tirinhas (mais curtas) ou quadrinhos mais longos, como em revistas, álbuns e livros, a depender da finalidade pedagógica.

A relação entre HQs com a educação científica se deu, segundo Tavares Júnior (2015), em 1950 com as revistas Ciências em quadrinhos e Enciclopédia de Quadrinhos, continuando em 1959 com a publicação da revista de Ziraldo Saci Pererê - que tratava sobre cultura popular e fauna brasileira. Em 1990, a editora Abril publica Proteus- A aventura das Ciências em Quadrinhos, que almejava o desenvolvimento de futuros cientistas no contexto histórico e cultural da época; assim, por meio de aventuras de ficção científica, buscava-se a valorização do pensamento científico.

Segundo Santo e Vergueiro (2012), as HQs são utilizadas no ensino de diferentes campos do conhecimento: Artes, História e Ciências. Os autores complementam que empreender aulas práticas com HQs deixa o aprendizado mais prazeroso, dinamizando-o. Neste estudo, nosso enfoque é o campo da Biologia. Na próxima seção, analisaremos as contribuições das HQs para o ensino de Biologia.

\section{HQs e ensino de Biologia: trabalhos relacionados}

No campo da Biologia, diferentes perspectivas quanto à abordagem de HQs no ensino vêm sendo investigadas. O estudo de Silva e Costa (2015) investigou como as tiras 
do personagem Níquel Náusea são utilizadas como ferramenta didática no ensino de Biologia. Os autores realizaram a análise do conteúdo de 1.115 tiras, chegando à conclusão 3,4\% deste material é destinado ao ensino de Evolução Biológica. O material possui alguns erros conceituais propositais, que permitem que os professores da disciplina abordem o conteúdo de forma ilustrativa, crítica e metalinguística, mediando a aprendizagem dos estudantes a partir do uso do material com seus estudantes.

Desde a formação inicial de professores de Biologia, evidencia-se a relação entre HQs e ensino. Assim, o estudo de Tavares Júnior (2015) investigou as HQs como recurso didático no ensino da disciplina, a partir da visão de graduandos. Como resultados, o pesquisador evidencia como esses professores, desde a formação inicial, já conseguem identificar erros conceituais propositais em tirinhas, assim como a linguagem típica das HQs, suas imagens e valores que são transmitidos de modo "oculto", baseados nos valores particulares dos autores.

Em termos práticos, o estudo de Toledo et al., (2016) investigou como o ensino de Imunologia pode ser mediado pelo uso de HQs, revelando que o uso delas auxilia no processo de ensino dos diferentes tipos celulares da imunidade inata (macrófagos) e adquirida (Linfócitos T e B), a partir da temática Imunidade a parasitas adquiridos por alimentos - no gibi criado para este propósito e chamado Julia Imune.

Mehes e Maistro (2012) investigaram como diferentes conteúdos de Biologia podem ser contextualizados para aprendizagem de estudantes no ensino médio: Sistema Cárdiorrespiratório, a partir do gibi da HQ Turma da Mônica; Classe dos Insetos, a partir da HQ Garfield de Jim Davis e Divisão celular Mitose, a partir da QEBIO.

Iniciativas interdisciplinares também já foram tomadas. O estudo de Santos et al. (2012), contextualizou o ensino de Biologia e Química, a partir do uso de Tecnologias Digitais para a produção HQs, com o conteúdo Reciclagem do óleo, contemplando, assim, as duas áreas do conhecimento. Os autores utilizaram o programa Pixon (para escolas) para produzir HQs sobre a temática com os estudantes. Apenas as turmas do terceiro ano consideraram a atividade desnecessária e os autores inferem que a preparação para o Exame Nacional do Ensino Médio (Enem) influenciou nesse resultado; entretanto, é justamente nesse exame, que as HQs estão sendo requeridas como uma das habilidades interpretativas exigida dos estudantes. 
A partir da apresentação destes trabalhos, constatamos o interesse da articulação entre HQs e o ensino de Biologia, em diferentes níveis educacionais e perspectivas. Observamos, também, que as TD podem auxiliar no processo de criação de HQs, a exemplo do trabalho de Santos et al (2012). Neste contexto, na próxima seção, apresentaremos caminhos que promovem o diálogo entre o ensino de Biologia no contexto atual de pandemia Covid-19 e pós-pandemia, a partir do uso de aplicativos para produção de HQs, que podem enriquecer as aulas remotas e, no contexto pós-pandêmico, as aulas presenciais.

\section{Pandemia Covid-19, aulas remotas emergenciais e HQs:uma combinação possível?}

A pandemia causada pelo novo coronavírus (SARs-CoV-2) promoveu mudanças abruptas no cenário educacional: aulas presenciais em escolas e universidades foram suspensas e as aulas remotas emergenciais foram desenvolvidas por meio de lives (gravações de vídeos ao vivo) (ARRUDA, 2020). Moreira et al. (2020) acrescentam que esta transição das aulas presenciais para às remotas ocorreu de modo obrigatório e que as instituições de ensino passaram a utilizar diferentes plataformas para o auxílio destas aulas em um contexto síncrono e assíncrono: Youtube, Skype, Google Hangout e Zoom para as lives; Moodle, Microsoft Teams e Google Classroom, para complementar as aulas presenciais, em um contexto assíncrono.

Para Arruda (2020), as aulas remotas emergenciais foram necessárias porque permitem que professores e estudantes estejam conectados, salvo exceções, durante o período pandêmico. Para o autor, sem estas aulas a qualidade da educação estaria comprometida, devido aos meses sem interação entre seus atores, o que causaria um estranhamento no retorno após meses sem contato.

No contexto de aulas emergenciais assíncronas, apresentadas por (MOREIRA et al., 2020), onde os sujeitos da Educação não interagem presencialmente (ARRUDA, 2020), podemos pensar sobre como as HQs podem auxiliar o ensino no cenário atual e após o término da pandemia Covid-19. Motta e Correia (2013), discutem sobre como as HQs migraram do contexto impresso ao digital. Postulam, também, que, além de sites, as HQs digitais podem ser encontradas em aplicativos para aparelhos móveis e tablets, além de fazerem parte da introdução de jogos digitais e aparecendo em filmes e animações. 
Ao considerarmos o conceito de ensino trazido por Tardif (2014), como uma ação que promove a interação entre grupos de estudantes, atingindo objetivos ligados ao conhecimento e à socialização, entendemos que no contexto atual de pandemia as HQs digitais (MOTTA; CORREIA, 2013) podem ser uma das alternativas para enriquecer as interações entre estudantes e professores em um cenário assíncrono (MOREIRA et al., 2020). O ensino híbrido, já discutido antes da pandemia Covid-19 e em aulas presenciais, mesclado com as TD (MORAN, 2015) representa um dos meios em que elas estarão mais presentes nas salas de aula. Assim, as HQs digitais podem ser uma das alternativas de ensinar nestes dois contextos. Discutiremos sobre estas questões sob a ótica das percepções de professores de Biologia imersos no ensino remoto emergencial atual. Dessa forma, revela-se as potencialidades reais de desenvolvimento de estratégias de ensino, mediadas pela criação de HQs digitais a partir de aplicativos.

\section{Caminhos metodológicos}

Este estudo possui abordagem qualitativa com delineamento exploratório. $\mathrm{Na}$ abordagem qualitativa os resultados não são alcançados por meio de procedimentos estatísticos ou outros meios de quantificação (CORBIN; STRAUSS, 2008). Busca-se, também, compreender as condições de vida das pessoas, suas opiniões e impressões, as condições contextuais em que vivem, as relações entre conceitos existentes e emergentes, baseando-se em múltiplas fontes de evidência (YIN, 2016). O delineamento exploratório é voltado para estudos cujos temas ou problemas são pouco compreendidos ou em que existem muitas dúvidas que não foram abordadas antes- uma vez que em fenômenos desconhecidos ou novos precisam ser investigados (SAMPIERI et al., 2013).

Em nosso contexto, a pandemia Covid-19 provocou ineditismo em termos de mudanças em setores sociais, inclusive na Educação e em processos de ensino e aprendizagem (ARRUDA, 2020). Dentro deste cenário mais amplo, de maneira mais específica, a relação entre criação de HQs digitais e ensino remoto de Biologia ainda não foi abordado. Esse fato foi confirmado ao buscarmos no Portal de Periódicos da Coordenação de Aperfeiçoamento de Pessoal de Nível Superior (CAPES) se do início da pandemia Covid-19 até o mês atual algum estudo foi publicado sobre o tema, porém nenhum resultado foi encontrado - o mesmo ocorreu ao realizarmos buscas no Google 
Acadêmico. Assim, este estudo visa preencher esta lacuna inicial por meio das percepções dos professores de Biologia que estão imersos no contexto atual de ensino na pandemia Covid-19.

Participaram deste estudo cinco professores de Biologia, atuantes nas redes públicas e privadas da Cidade Maceió-AL. O critério de inclusão dos sujeitos foi: que estivessem atuando no ensino remoto emergencial no contexto da pandemia Covid-19. O critério de exclusão foi: professores que não estivessem atuando neste contexto e/ou que não se interessassem pela relação HQs e ensino de Biologia. De uma amostra de seis professores contatados, apenas cinco se interessaram pelo estudo. Foi dado a esses professores o Termo de Consentimento Livre e Esclarecido (TCLE), de modo que pudessem compreender o objetivo deste estudo e, assim, contribuir para o desenvolvimento dele. Para preservar suas identidades, os professores foram identificados pelas letras: A, F, J, M e W.

$\mathrm{Na}$ primeira fase da pesquisa realizamos entrevistas semiestruturadas com os sujeitos do estudo com duração média de meia hora, cada. Indagamos sobre suas vivências (ou não) com HQs, bem como sobre possíveis caminhos estratégicos para o ensino sobre a doença Covid-19, a partir da criação delas com os seus estudantes. Ao transcrevê-las, devolvemos os dados brutos aos entrevistados, de modo que eles verificassem se o que disserem correspondia ao que realmente queriam ter dito. Esse procedimento metodológico evita que impressões subjetivas do pesquisador sejam colocadas posteriormente na análise e interpretação de dados qualitativos, enviesando-os, além de ser uma postura ética (SZYMANSKY, 2011).

Os dados foram analisados com a técnica análise do conteúdo (BARDIN, 2011), dividida em: (a) pré-análise: a partir de uma leitura flutuante, temos as primeiras impressões em torno do texto e de possíveis novas categorias; (b) exploração do material: consiste na codificação do material, selecionando trechos do texto e associando-os às suas categorias; (c) tratamento dos dados e interpretação: a partir dos gráficos ou diagramas resultantes do processo anterior, realiza-se inferência em torno dos achados de modo a responder ao problema da pesquisa. Utilizamos o software Atlas ti $7^{\circledR}$ para auxiliar as análises.

As categorias do estudo foram: 1) HQs e estratégias de ensino de Biologia; 2) HQs e ensino Remoto emergencial; 3) Aplicativos de HQs e ensino de Biologia. O estudo foi 
desenvolvido em duas fases: a primeira consistiu na análise das percepções dos professores em torno do ensino de Biologia mediado pela criação de HQs,a partir das entrevistas semiestruturadas; a segunda consistiu em selecionar e analisar um aplicativo mencionado nas entrevistas, analisando sua potencialidade pedagógica para o ensino da disciplina. Considerou-se a acessibilidade desse aplicativo para os sujeitos do processo pedagógico e o aplicativo mais adequado, no contexto atual de ensino remoto emergencial (ARRUDA, 2020) e pós-pandemia, em um cenário híbrido (MORAN, 2015).

\section{Percepções de professores de Biologia sobre o ensino da Covid-19 mediado por aplicativos de criação de histórias em quadrinhos}

Nesta primeira fase, identificamos as percepções e estratégias dos professores de Biologia para o ensino sobre Covid-19, mediado por aplicativos de produção de HQs; relacionou-se, assim, esse processo ao contexto atual de aulas remotas emergenciais e póspandemia.

Ao questionarmos aos professores se eles já interagiram previamente com HQs, tivemos resultados diferenciados. O professor A afirmou que sim e que "fazia parte daquele universo". O professor F lia HQs norte-americanas e atualmente lê o estilo japonês mangá (HQ japonês em que se lê da esquerda para a direita). O professor J afirmou que só lia HQs na infância, mas atualmente não mais, e que um texto corrido o atrai mais. Contudo, tem curiosidade em torno de como pode abordar HQs em suas aulas. O professor $M$ afirmou que lia na infância e que atualmente voltou a ler, a partir de um projeto com HQ que desenvolveu na escola antes da pandemia. O professo $\mathrm{W}$ afirmou, também, que lia na infância e que este foi o primeiro tipo de literatura que teve contato.

Esses achados confirmam os pressupostos de que as HQs são associadas à infância, mas não restritas a ela (VERGUEIRO; RAMOS, 2009). Baseado nesses primeiros achados percebemos que os professores de Biologia associaram a experiência com HQs à infância. Entretanto, mesmo que o gosto por esse tipo de leitura tenha mudado, como evidenciado na fala do professor J, o interesse para objetivos pedagógicos ainda está presente e os preconceitos relacionados a esses artefatos não se evidenciam nos sujeitos deste estudo.

Ao questionarmos como as HQs podem influenciar o ensino de Biologia, chegamos aos seguintes resultados: o professor A afirmou que "as HQs fazem referências a crianças, 
adolescentes e jovens da geração atual [...] vejo como um recurso favorável quando se pretende contextualizar o ensino de Biologia". O professor F enfatizou as narrativas, ao afirmar que "muita coisa em Biologia pode ser feita em forma de narrativas [...] você consegue fazer o storytelling e narrar histórias" e acrescenta: “As HQs podem ser um meio para contar histórias sobre como um pesquisador teve ideia para fazer um experimento, viagens de pesquisadores como Darwin". O professor J afirmou que, enquanto professor de Biologia, percebe que seus estudantes gostam de literatura em HQ, como mangás, e que se pode aproveitar a situação para abordar HQs biológicas ao afirmar que "eu já li HQs sobre a origem do remédios/fármacos, algumas doenças, meio ambiente [...] mas eu vejo o aluno mais ativo, produzindo a HQ, mas isso depende de professor para professor". O professor $M$, por outro lado, afirmou que "acredito que as HQs influenciam na investigação: os alunos precisam criar narrativas, histórias, precisando investigar. Ao se contextualizar um conteúdo, eles vão se aprofundar mais nas pesquisas". Por último, o professor W afirmou que pode ajudar na contextualização do conteúdo, uma vez que "estas histórias podem despertar a identificação de quem lê com inúmeras situações e agradar vários gostos literários enquanto percorre o conteúdo".

Esses achados concordam com os resultados do estudo de Mehes e Maistro (2012), ao investigarem como conteúdos de Biologia podem ser contextualizados em HQs, por se aproximarem do cotidiano dos jovens adolescentes do ensino médio. Nossos resultados, contudo, evidenciam a ótica dos professores; confirma-se que, também, para estes sujeitos as HQs aproximam a vida cotidiana ao conhecimento científico biológico e, em uma perspectiva de produção, podem promover o espírito investigativo nos estudantes. Percebeu-se, também, que biografias de cientistas como Charles Darwin podem ser estudadas e traduzidas na forma de HQ.

Ao questionarmos os professores se seus estudantes estranhariam a estratégia de ensino de Biologia mediada por HQ, chegamos aos resultados: o professor $\mathrm{A}$ afirmou que estranhamentos a recursos didáticos são comuns e que "é normal. Muitas vezes o simples uso de um vídeo já desperta estranhamento. O uso de HQs vai levar estranhamento [...], mas a acomodação vem com o tempo de uso do próprio recurso". O professor $\mathrm{F}$ afirmou que o entretenimento geralmente é muito desligado do estudo e que "é uma barreira que pode ser superada ao perceberem que dá para usar (HQ)". O professor J menciona que depende do perfil do estudante, mas que podem ficar surpresos e que "apenas uma minoria vai dizer 
'ah, isso é coisa de criança' [...]...lógico que se formos trabalhar com o ensino médio não vamos infantilizar a HQ utilizando a turma da Mônica, mas deixar algo mais adulto. Isso depende do personagem que estamos apresentando". O professor M concorda com o professor A e J ao afirmar que "causa estranhamento por causa da rotina. Mas com HQ pode ser estranho porque há uma visão de que seja só para crianças e não se aplique à galera do ensino médio”. O professor W conclui “talvez. A HQ tradicional ficou infantilizada e o mangá tem um gênero de consumidores mais específico [...] algumas atividades de leitura gera descontentamento na maioria dos estudantes".

Esses resultados reafirmam a preocupação metodológica de Santos e Vergueiro (2012) quanto à faixa etária que as HQs são destinadas: o professor, conhecedor de títulos e nuances das HQs, deve selecionar as mais adequadas para o contexto do ensino médio, como as falas dos sujeitos deste estudo evidenciam. Sem essa preocupação, a atividade pode ser estranhada pelos adolescentes que acabam reduzindo-a a uma atividade infantil. Esse, portanto, é também um cuidado a ser considerado em um processo criativo com HQs.

Quanto ao conhecimento de aplicativos de criação de HQs, o professor A afirmou que não conhece e que neste contexto de criação só viu um colega de trabalho na área de exatas realizando atividades com aplicativos. Ele acrescenta: "das vezes que lancei mão das HQs, em determinados contextos de aula, imprimi modelos já prontos da internet". O professor $F$ também afirmou que não conhece aplicativos, mas que existe um site de produção cujo nome não se recorda. E acrescenta: "estou interessado em aplicativos [...] se for um fácil, porque, tipo, eu sou horrível desenhando [risos]". O professor J afirmou que "eu sei que existe. Mas nunca vi um”. O professor M afirmou que conhece o aplicativo MangáMaker e que já o utilizou com seus estudantes no contexto presencial. Por último, o professor W afirmou que "já tive contato com alguns, mas não me recordo os nomes".

Estes achados indicam uma lacuna que pode ser preenchida na segunda fase deste estudo: os professores não interagem muito com aplicativos de criação de HQ, com exceção do professore $M$, que mencionou o MangáMaker. O professor $A$, ainda que não tenha mencionado qual $\mathrm{HQ}$ utilizou da internet para uso em suas aulas, pode ter usufruído de tiras do Níquel Náusea, uma vez que ela é recorrente para o ensino de Biologia (SILVA E COSTA, 2015), além de possuir um site disponível com muitos exemplos (http://www.niquel.com.br/). 
Ao questionarmos qual plataforma estão utilizando nas aulas emergenciais, chegamos aos resultados: o professor A afirmou que "iniciamos com aulas gravadas, com captura de tela do Power Point (pouco eficiente). Então usamos o Zoom com tempo limitado de aulas (40min) e pela tecnologia dos celulares dos estudantes não permitia acesso às aulas. Então estamos utilizando o Google Meet". O professor F afirmou que "a plataforma 'oficial' é o Google Sala de aula e a 'oficiosa' é o WhatsApp[risos]". O professor J afirmou que "no início eram emergenciais. Atualmente são intencionais porque a escola já está se preparando para isso de maneira mais objetiva. Na rede particular, estamos utilizando o GoogleClassroom e o Zoom para aulas síncronas. No Estado, blog e WhatsApp" O professor M afirmou que estão utilizando o Google Classroom, assim como o professor W, com o complemento do WhatsApp para acompanhar as atividades.

De modo geral, Google Meet, Google Classroom e Zoom são as plataformas utilizadas pelos professores deste estudo para a realização de suas aulas remotas, no contexto da pandemia Covid-19, reafirmando os pressupostos de Arruda (2020) e Moreira et al. (2020). Estas pistas indicam os modos em que podemos abordar a criação de HQs no contexto atual, uma vez que estas aulas podem ser desenvolvidas de forma síncrona e assíncrona, neste último caso, em fóruns de discussão (MOREIRA, et al., 2020), a partir dos resultados apresentados pelos estudantes.

Ao questionarmos os professores como eles concebem o uso de aplicativos para produções de HQs online, em um contexto de isolamento social em que a produção de $\mathrm{HQ}$ não pode ocorrer presencialmente, chegamos aos seguintes resultados: o professor $A$ mencionou que por serem aplicativos, "podem ser manipulados por celular ou PC, agregando [valor] às aulas remotas como atividades lúdicas, desde que não fujam do contexto de ensino e aprendizagem, incentivando a criação de estudos práticos, criatividade e cognição [dos estudantes] [...]". O professor $F$ afirmou não conhecer nenhum aplicativo, mas a depender das possibilidades, "pode-se digitalizar HQs produzidas no papel, caso tenham conexão à internet para enviar suas produções".

O professor $\mathrm{J}$ mencionou que se fosse construir uma atividade, passaria um desafio em que "os estudantes construíssem um roteiro, com personagens, envolvendo a Covid-19 ou outros mecanismos biológicos, apresentando os resultados em uma aula assíncrona ou online, no Google Classroom ou Google Meet". O professor M, por outro lado, lança outro olhar sobre a atividade online com HQ quando comparada à presencial, uma vez que "na criação 
de uma HQ em que os alunos, os atores, estariam presentes, trocando ideias juntos [no presencial] perca um pouco a qualidade [no online], pois vai depender de uma 'cabeça' fazendo [a atividade]". O professor W afirma que a proposta por aplicativo é relevante, mas não sabe se usaria, uma vez que "nem todos os alunos têm acesso à internet e/ou smartphones. [...] do meu ponto de vista, é mais viável trabalhar com HQs prontas e debater as ideias a partir dessas histórias e somente depois se concentrar naqueles [estudantes] que podem desenvolver por aplicativo".

Estes achados, em torno do uso de aplicativos de produção de HQ durante as aulas remotas, dividiram perspectivas entre os professores. As percepções dos professores A e J se aproximam do pensamento crítico em relação ao uso de HQs (SANTOS; VERGUEIRA, 2012), já que devemos analisar o contexto de ensino e aprendizagem em que a proposta está sendo direcionada, ao mesmo tempo em que enfatizamos as interações entre os estudantes (TARDIF, 2014). A perspectiva do professor F dialoga com Motta e Correia (2013) como uma das formas de produção de HQs menos interativa. O professor J articula sua prática de ensino remoto por meio de lives (ARRUDA, 2020), com o contexto do ensino híbrido (MORAN, 2015). Essas aulas correspondem àquelas ensinadas presencialmente. As atividades devem ser enriquecidas a partir do uso de aplicativos de produção de $\mathrm{HQ}$ — para aprendizagem assíncrona dos estudantes - , complementando os seus estudos. As falas dos professores $\mathrm{M}$ e W apontam para uma melhor adequação da proposta no contexto presencial híbrido (MORAN, 2015), já que mesmo estudantes que não podem ter acesso às TD, podem, presencialmente, desenvolver estudos em grupos com estudantes que possuem essas tecnologias, enriquecendo, assim, as aulas presenciais. A questão da acessibilidade é, contudo, um fator a ser considerado para práticas com aplicativos no contexto de aulas remotas atuais.

Ao questionarmos os professores sobre quais possíveis caminhos estratégicos para o ensino sobre a doença Covid-19 - a partir do uso de aplicativos - para a criação de HQs pelos estudantes, os resultados foram os seguintes: o professor $A$, previamente à pandemia Covid-19, já discutiu com seus estudantes sobre ações imunitárias em suas aulas, mas a partir do uso de HQs da Marvel®, em que tratou os processos celulares (leucócitos) e dos antígenos como personagens do filme "Os Vingadores", no episódio "Guerra Infinita" da saga. Contudo "como foi apresentação pronta, não houve outra participação, por parte dos alunos, senão a abstração de relacionar os mundos (imunológico e fictício)" e o professor 
acrescentou "na criação de HQs envolvendo Covid-19, pode-se criar a história 'evolutiva' do vírus, buscando meios científicos para justificar a sua modificação estrutural que o tornou tão virulento e 'resistente' a uma resposta imunológica". O professor $\mathrm{F}$, por outro lado, afirma enxergar dois caminhos em que o ensino pode ser mediado por meio da criação de HQs: "criar uma HQ sobre como a doença se espalha e como pessoas são contaminadas, sem explorar gráficos ainda, mas compreender a partir do cotidiano atual como é a doença do ponto de vista epidemiológico; e ele acrescenta "a segunda linha narrativa seria sobre as pesquisas do ponto de vista de um médico, pesquisador, enfermeiro(a) do dia-a-dia dos hospitais e como lidam com a situação e com o uso de remédios como a cloroquina". O professor J, por outro lado, passaria desafios em formas de missões para turmas do segundo ano, que estudam vírus e bactérias, com o prazo de quinze dias para investigarem sobre o tema Covid-19 e produzir o roteiro;deveria ser realizada uma revisão desde o início até o momento atual em que "os estudantes poderiam esclarecer a partir da realidade dele, as dúvidas mais frequentes e como a Biologia pode auxiliar no combate às Fake News sobre o assunto".

O professor M acrescenta às estratégias “termos videoconferências, trocando ideias, podendo, assim, construir uma narrativa remotamente [...] realizando pesquisa sobre como combater a Covid-19, juntando ideias e traduzi-las em forma de HQ, levando as informações para o maior número de pessoas de forma atrativa, mas ao mesmo tempo correta [cientificamente]". O professor W já acrescenta "eu gosto do contexto histórico [sobre o vírus]. De início, entender sobre os vírus e sobre como o Sars-Cov-2 chegou a humanos seria interessante. Poderíamos abordar, portanto, esse contexto histórico e o cenário atual" e adiciona "criar o próprio final feliz [na narrativa da HQ] pode ser ingenuidade, mas ajuda a manter a esperança e sensibilizar nossos estudantes [...] tudo criação e pesquisa deles [estudantes] e eu como professor só indicando os caminhos" e finaliza "A HQ poderia ser distribuída em plataformas digitais depois".

Estes achados reafirmam o papel das HQs na Educação científica (TAVARES JÚNIOR, 2015), em que os professores de Biologia pensam no ensino da disciplina em uma perspectiva de promover interações entre os estudantes (TARDIF, 2014). Estes resultados indicam o interesse do ensino sobre o sistema imunológico, como verificamos na fala do professor A, o que o estudo de Toledo et al. (2016) já havia evidenciado. Também que os professores buscam proximidade com os estudantes, como verificado na perspectiva do 
professor $\mathrm{M}$ em criar, conjuntamente com os estudantes, a narrativa do HQ por meio de videoconferências. Neste contexto, os atores educacionais estabelecem uma aproximação no cenário pandêmico (ARRUDA, 2020).

Ao questionarmos a partir da estratégia anterior se os professores explorariam somente a dimensão biológica da Covid-19 ou também outros campos do conhecimento, chegamos aos seguintes resultados: o professor $A$ afirmou que discutir sobre a evolução do vírus exige uma compreensão maior que a biológica, isoladamente, sendo necessário "compreender o contexto social, geográfico e histórico, os avanços tecnológicos e a dinâmica econômica que envolve o avanço científico e acadêmico" e conclui "diferentes áreas têm que ser abordadas quando se desenvolve uma estratégia didática com HQ”. Concordando com o professor A, o professor F afirmou que "tem que abordar o ponto de vista sociológico, impactos em famílias, comparando do ponto de vista histórico com a última pandemia; do ponto de vista químico, como se consegue isolar e criar substâncias que podem ser usadas no combate [à doença]; geográfico (disseminação) e geopolítico (como cada país reage e o porquê dele reagir de determinada forma). No mesmo pensamento, o professor J afirma que na Escola Estadual em que trabalha, está abordando a Covid-19 nas dimensões biológica, química e também social. Em sua fala "englobaria outras disciplinas, se os outros professores aceitassem". O professor M acrescenta "falaria não só da parte biológica, mas de questões que são inerentes a ela: afeto, como é está sozinho, como resolver problemas decorrentes da pandemia, os econômicos" e finalizando, o professor W afirma "qualquer campo do conhecimento é válido para trabalhar com HQ".

Estes resultados dialogam com os trazidos no estudo de Santos et al. (2012), ao discutirem sobre como pode ocorrer a criação interdisciplinar de uma HQ mediada por TD, envolvendo as disciplinas Biologia e Química. Neste estudo, os professores também visualizam esse processo criativo com outras áreas do conhecimento, o que pode enriquecer o resultado almejado em torno de uma HQ sobre Covid-19.

Ao questionarmos como os professores mediariam a estratégia de ensino sobre Covid-19 com a produção de HQs e o ensino remoto emergencial em que estão imersos, chegamos aos seguintes resultados: o professor $A$ afirmou que os recursos disponíveis são as plataformas digitais, então usaria o Google Meet que "permite o compartilhamento de tela, exibir vídeos e comentá-los. Durante o tempo de aula/apresentação, fazemos reflexões acerca de textos sobre o avanço da doença. Um dos modos de discussão seria a criação de 
HQs, discutindo sobre as possibilidades de saída da situação atual”. O professor F afirmou que "a partir das aulas remotas articuladas com HQs não se sabe se dá para ter algo muito prático, uma vez que não sabe se todos os estudantes possuem todos os recursos [tecnológicos] requeridos; o professor J, contudo, afirmou que é possível criar HQs através de aulas remotas, a partir da realidade que está inserido e que seria um trabalho processual com um prazo maior, envolvendo as etapas de produção, como roteiros, personagens, etc. Em suas palavras “eu ia mediando, lançando perguntas e desafios”. O professor M afirmou que não teria dificuldades, uma vez que já vem desenvolvendo outras atividades mais práticas com os estudantes, como a produção de infográficos. O professor $\mathrm{W}$ afirmou o mesmo.

Estes achados indicam que os professores que participaram deste estudo são familiarizados com as TD e que, por meio das plataformas mencionadas, o processo de produção de uma HQ sobre Covid-19 seria viabilizado, salvo exceções em que os estudantes não tenham acesso às TD. Essa produção poderia ocorrer de forma síncrona ou assíncrona (ARRUDA, 2020), uma vez que o professor A menciona o Google Meet, e o professor J indica uma produção processual, em que se pode inferir que seja por meio do Google Classroom que ele utiliza em sua escola, como mencionado no início das entrevistas. Podemos também afirmar que as TD aproximam professores e estudantes em tempos de pandemia (ARRUDA, 2020), e que a produção de HQs pode ser uma das formas alternativas disto ocorrer — no contexto de ensino e aprendizagem.

Por último, questionamos aos professores de Biologia se no contexto atual de isolamento social — nas plataformas de ensino em que estão realizando as aulas remotaseles priorizariam atividades individuais ou em grupos; perguntamos, também, sobre a criação de HQs utilizando aplicativos e como abordariam a estratégia no contexto presencial. Chegamos aos seguintes resultados: o professor A, afirmou que, apesar do isolamento social físico estar em vigor, nada impede que os estudantes se reúnam digitalmente. Contudo, podem existir fatores que podem impedir o andamento da criação, como problemas de conexão à internet. Assim, "analisando a problemática, a preferência tem sido trabalhos/atividades individuais, respeitando as condições econômicas dos estudantes como pacotes melhores de acesso à wi-fi”. E acrescenta: “após a pandemia, poderia desenvolver a atividade no laboratório de informática ou à distância, realizando discussões em sala de aula depois". Concordando com o professor A, o professor F esclarece 
que gostaria de promover atividades em grupo, mas a partir da realidade atual, existe uma redução de estudantes participando ativamente das aulas e que "eles não trabalhariam bem em grupos [nas condições atuais][...] então na prática levaria para o lado individual, mas incentivando sempre o lado colaborativo, mas sem esperar que eles façam isso forçado" e quanto às atividades após a pandemia, continuaria com o uso de aplicativos e com discussões em sala de aula.

O professor J afirmou que promoveria a criação de HQs por meio da formação de trios de estudantes, porque o futuro da Educação é trabalhar colaborativamente. Em suas palavras: "quando temos um problema, devemos trabalhar em conjunto [...] cada grupo terá habilidades ou skillsofts diferentes: enquanto um [estudante] tem habilidade para construir, outro tem habilidade para criar roteiro, outro, personagens [...]". Concordando com o professor J, o professor M acrescenta: "em grupo [...] para ficar algo mais diverso e uma construção que possa avaliar as várias ideias que existirão, e traçar o que está em comum a todos". O professor M ainda acrescenta "Em minhas aulas remotas, os resultados poderiam ser compartilhados na forma de videoconferências. Na parte assíncrona, a base da HQ poderia ser construída por meio de wikis, definindo história, roteiro, personagens". Ambos os professores afirmam, que no contexto pós-pandemia, a criação de HQs enriqueceria aulas presenciais.

No cenário delineado pelos professores de Biologia, as atividades em grupo ou individuais em torno da produção de uma HQ em suas aulas remotas são válidas, visto que o contexto de cada um varia. Assim, os resultados do estudo indicam que atividades em grupo são viáveis quando há acessibilidade (ARRUDA, 2020); quando não há acessibilidade, as atividades individuais são preferíveis. Os dados também apontam que o ensino híbrido (MORAN, 2015) será uma tendência fortalecida após a pandemia, visto que todos professores afirmam que a criação de HQs por meio de aplicativos poderia ocorrer em sala de aula presencial, enriquecendo-a.

A partir destes primeiros achados nestas entrevistas, constatamos que, à exceção do professor $M$, os outros professores não conheciam aplicativos de produção de HQs. Neste sentido, passamos para a segunda fase do estudo: analisar aplicativos que possibilitem aulas remotas emergenciais por conta da pandemia Covid-19; assim, em um contexto híbrido, esses aplicativos devem enriquecer as aulas presenciais. 


\section{Aplicativos de produção de produção de HQs: uma exploração no Google Play}

A escolha do Google Play como plataforma de pesquisa para aplicativos de HQ se justifica porque 0 site hospeda aplicativos para diferentes propósitos (https://play.google.com/store/apps). Ao digitarmos na guia de busca "Aplicativos de Histórias em Quadrinhos", 244 resultados apareceram. Deste total, só analisamos os aplicativos que possuíssem o selo de verificação do Google Play, que recomenda aqueles mais baixados pelo público (Figura 1). Assim, somente três foram selecionados.

Figura 1- Exemplo de aplicativo do Google Play com selo de verificação

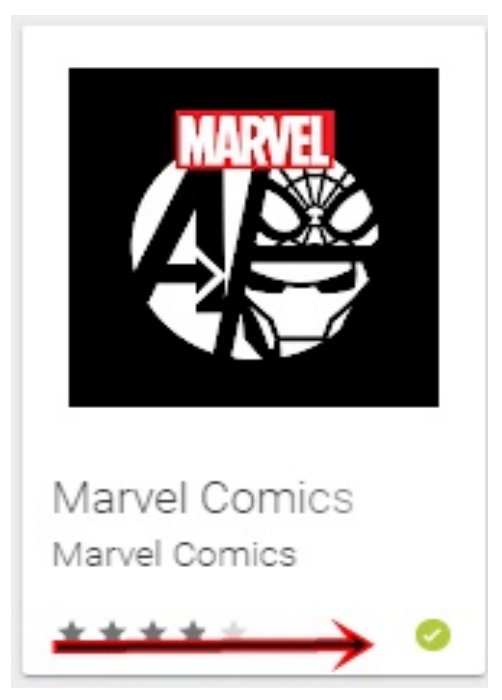

Fonte: Google Play

Os três aplicativos selecionados foram: Marvel Comics, Comic\&MemeCreator, e Comica-Transforme suas fotos em quadrinhos, todos gratuitos. Analisamos todos ao realizar download para o celular. O aplicativo mais apropriado para as aulas remotas emergenciais é o Comica-Transforme suas fotos em quadrinhos; isto se justifica porque, dentre os três aplicativos, este é o mais intuitivo. Os demais, além de estarem em língua inglesa, não são fáceis de navegar para quem não domina o idioma. Este mesmo problema foi verificado ao analisarmos o aplicativo "MangáMaker3" mencionado pelo professor M em sua entrevista: o idioma do software é o inglês, o que pode dificultar a atividade para alguns estudantes. Assim, para a proposta de ensino de Biologia em que os professores pretendem estimular interações entre os estudantes (TARDIF, 2014), este é o mais adequado para o propósito.

3Para maiores informações, acessar: https://www.rpgmakerweb.com/products/programs/manga-maker-comipo. 
A figura 2 mostra a capa do aplicativo e alguns exemplos dos resultados que ele promove em pouco tempo de uso.

Figura 2- Aplicativo Comica e alguns exemplos de resultados de seu uso

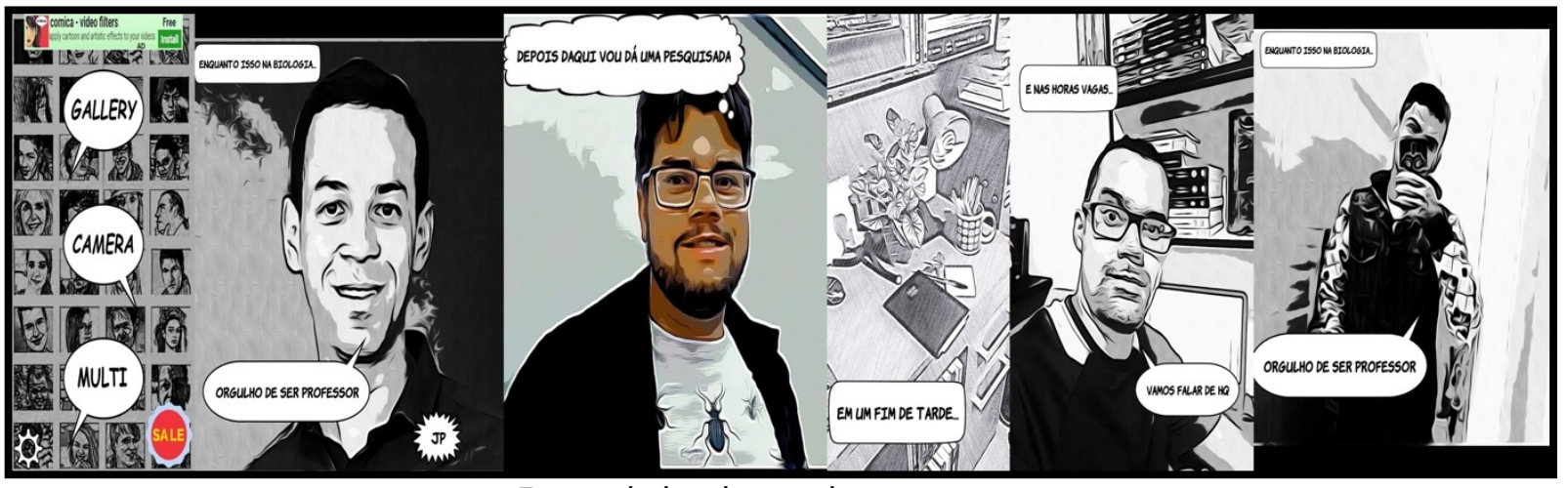

Fonte: dados do estudo.

O uso do aplicativo consiste em tirar fotos e transferi-las para a narrativa que está sendo criada. Dentro do aplicativo, existem opções em relação ao padrão da arte a ser seguida, podendo ser colorida ou não. O estudante pode fotografar ambientes ou pessoas para serem os personagens da história, podendo se expressar textualmente por meio dos balões de fala, pensamentos ou aqueles ligados à narrativa, promovendo assim a criação de uma HQ. O aplicativo funciona com todos os sistemas operacionais para celulares. Os estudantes que não consigam participar da atividade mediada pelo celular poderão participar das discussões em torno dos resultados obtidos por computador de mesa (PC). A figura 3 mostra os perfis de quadrinhos em que as narrativas podem ser construídas.

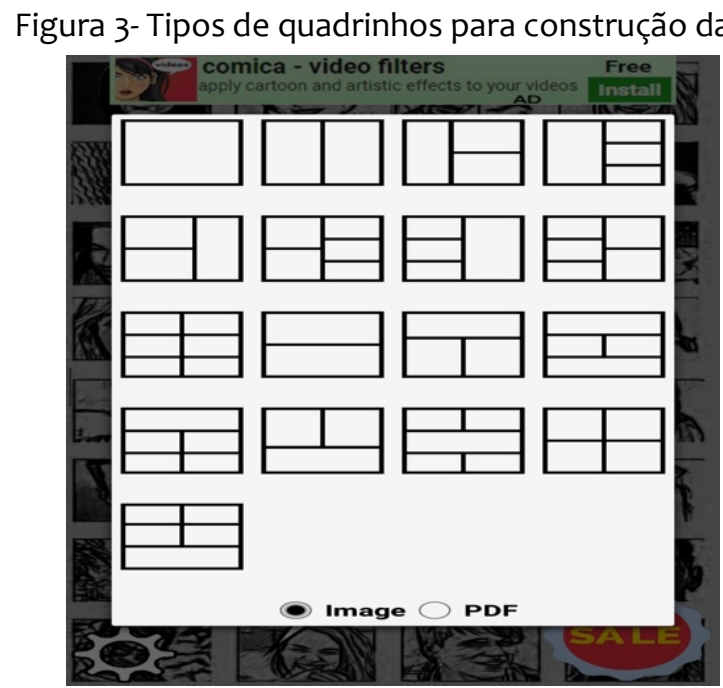

Fonte: Dados do estudo 
A partir da análise deste aplicativo, concluímos que as produções que podem ser elaboradas pelos estudantes podem ser colocadas para discussão no Google Classroom ou em outra plataforma do contexto de aulas remotas emergenciais - como foi evidenciado nas entrevistas dos professores. Pode-se, também, enriquecer as aulas presenciais em uma perspectiva híbrida, com o uso de TD (MORAN, 2015), após o término da pandemia Covid19.

\section{CONSIDERAÇÕES FINAIS}

A partir da identificação das percepções dos professores de Biologia, em torno de caminhos estratégicos para o a criação de HQs sobre a doença Covid-19, em aulas remotas emergenciais e presenciais no contexto pós-pandemia, e da análise de aplicativo com a finalidade de criação e que se enquadrasse nas condições atuais de ensino em plataformas emergenciais, contatamos que a hipótese deste estudo foi confirmada: os professores de Biologia deste estudo conseguem conceber estratégias de ensino sobre Covid-19 mediadas por aplicativos de criação de HQs, a partir das aulas remotas que estão realizando atualmente e para o contexto de pós-pandemia.

Os caminhos estratégicos de ensino trilhados pelos professores consideram: (1) a faixa etária a que a HQ será direcionada e a contextualização do ensino de Biologia como, por exemplo, a partir do resgate do surgimento do novo coronavírus até os dias atuais no conteúdo narrativo da criação da HQ por meio de aplicativo; (2) o desenvolvimento de atividades individuais e/ou em grupos, a depender da realidade escolar que estão inseridos e (3) as condições de acessibilidade que seus estudantes possuem em relação às TD, nas aulas remotas emergenciais ou presenciais.

Os achados deste estudo reafirmam os pressupostos que, ainda que HQs sejam ligadas diretamente às crianças, ganharam espaços para além do universo infantil. $\mathrm{O}$ interesse dos professores deste estudo em torno do objeto concorda com o pressuposto de que, ao se planejarem corretamente e de forma crítica, analisando a faixa etária do público a que se destinará a atividade, existem potencialidades de criação de HQs no contexto supracitado.

As entrevistas dos professores revelaram que estes sujeitos resgatam na infância experiências com HQs e que essas memórias são traduzidas na maneira de pensar possíveis estratégias de ensino sobre a doença Covid-19 em suas aulas remotas atuais. O estudo 
também revelou que estes sujeitos não apresentam dificuldades em usar TD e que a única objeção à estratégia de ensino mediada por aplicativo envolve a inclusão de todos os estudantes na mesma. Deste ponto, surgiu as diferentes percepções em torno dos caminhos mais adequados para desenvolvê-la, principalmente em termos de organização dos estudantes em grupos ou não.

A análise dos aplicativos do Google Play sustenta os pontos de vista estratégicos direcionados pelos professores nas entrevistas, ao menos no tocante ao uso do aplicativo Comica: disponível para download gratuito, fácil uso por ser intuitivo, além de não necessitar de uma compreensão profunda da língua inglesa para esta finalidade. Dessa forma, garante-se a acessibilidade, ao menos de estudantes que possuam smatphones. Este último dado nos faz refletir de que, para cada professor participante desta entrevista, existem realidades e contextos diferenciados, indicando que para uns, a estratégia de criação de HQs com aplicativos será viável porque seus estudantes possuem smartphones; para outros, a volta às aulas presenciais pode ser um dos modos de implementá-la, já que ela pode ser desenvolvida no contexto grupal em que quem possui o artefato tecnológico, poderá partilhar a experiência de criação com o outro estudante que não o possui.

Como próximas etapas deste estudo, pretendemos imergir nas aulas dos professores de Biologia com o aplicativo Comica, analisado neste estudo. Recomendamos que estudos experimentais sejam realizados com ele para o contexto atual de pandemia e pós-pandemia, seja na área de Biologia ou em outras áreas do conhecimento. Neste sentido, podemos afirmar que a Educação está mudando e que as HQs podem auxiliar em processos de ensino para o momento atual e futuro.

\section{REFERÊNCIAS}

ARRUDA, Eucidio P. Educação remota emergencial: elementos para políticas públicas na educação brasileira em tempos de Covid-19. Revista de Educação a Distância, v.7, n.1, p.257275, 2020.2 Disponível em: https://www.aunirede.org.br/revista/index.php/emrede/issue/view/15.Acesso em: 13 de jun. 2020.

BARDIN, Laurence. Análise do conteúdo. São Paulo: Edições 70, 2011.

CORBIN, Juliet.; STRAUSS, Anselm. Pesquisa qualitativa: técnicas e procedimentos para o desenvolvimento de teoria fundamentada. 2ed. Porto Alegre: Artmed, 2008. 
MEHES, Renata.; MAISTRO, Virgínia I. Aprendizagem de Biologia mediada por quadrinhos e charges. Pro-docência, v.1, n.1, p.1-20, 2012. Disponível em: http://www.uel.br/revistas/prodocenciafope. Acesso em: 29 jun. 2020.

MORAN, José. Educação híbrida: um conceito-chave para a educação, hoje. In: BACICH, Lilian.; TANZI NETO, Adolfo M.; TREVISANI, Fernando $M$ (org.). Ensino híbrido: personalização e tecnologia na Educação. Porto Alegre: Penso, 2015. p.27-46.

MOREIRA, José A.; HENRIQUE, Susana.; BARROS, Daniel. Transitando de um ensino remoto emergencial para uma educação digital em rede, em tempos de pandemia. Dialogia, São Paulo, n.34, p.351-364, 2020. Disponível em: https://periodicos.uninove.br/index.php?journal=dialogia\&page=article\&op=view\&path\%5 $B \% 5 D=17123$. Acesso em: 26 jun. 2020.

MOTTA, Rodrigo L.; CORREIA, Walter F. Design de histórias em quadrinhos digitais: criando novas mecânicas de leitura. In: ProcedingsofSBgames, 2016, São Paulo. Anais [...]. São Paulo: Universidade Presbiteriana Mackenzie, 2013. p.142-151. Disponível em: http://www.sbgames.org/sbgames2013/proceedings/artedesign/18-dtpaper_Design\%20de\%20HQ.pdf. Acesso em: 30 jun. 2020.

POSTEMA, Bárbara. Estrutura narrativa nos quadrinhos: construindo sentido a partir de fragmentos. São Paulo: Petrópolis, 2018.

SAMPIERI, Roberto H.; COLLADO, Carlos F.; LUCIO, Maria P. Metodologia de pesquisa qualitativa. Porto Alegre: Penso, 2013.

SANTOS, Roberto E.; VERGUEIRO, Waldemiro. Histórias em quadrinhos no processo de aprendizado. EcooS-Revista Científica, São Paulo, n.27, p.81-95, 2012. Disponível em:https://periodicos.uninove.br/index.php?journal=eccos\&page=article\&op=view\&path\% 5B\%5D=3498. Acesso em: 29 jun. 2020.

SANTOS, Victor J.; SILVA, Fernanda B.; ACIOLI, Mônica F. Produção de histórias em quadrinhos na abordagem interdisciplinar de Biologia e Química. Renote, v.10, n.3, p.1-8, 2012. Disponível em: https://seer.ufrgs.br/renote/article/view/36467. Acesso em: 29 jun. 2020.

SILVA, Edson P.; COSTA, Alan B. Histórias em quadrinhos e ensino de Biologia: o caso Níquel Náusea no ensino da teoria evolutiva. Revista de Educação em Ciência e Tecnologia, v.8, n.2, p.163-183, 2015. Disponível em: https://periodicos.ufsc.br/index.php/alexandria/article/view/1982-5153.2015v8n2p163. Acesso em: 29 jun. 2020.

SZYMANSKY, Heloisa. Entrevista reflexiva: um olhar psicológico sobre a entrevista em pesquisa. In: SZYMANSKY, Heloisa; ALMEIDA, Laurinda R.; PRANDINI, Regina C. (org.). A entrevista na pesquisa em Educação: a prática reflexiva. Brasília: Liber Livro, 2011, p.9-61.

TARDIF, Maurice. Saberes docentes e formação profissional. 17ed. Petrópolis: Vozes, 2014. 
TAVARES JÚNIOR, Melchior J. As histórias em quadrinhos (HQs) na formação de professores de Ciências e Biologia. Educação, v.40, n.2, p.439-450, 2015. Disponível em: https://periodicos.ufsm.br/reveducacao/article/view/14164. Acesso em: 29. jun. 2020.

TOLEDO, Karina A.; MAZALI, Gabriela S.; PEGORAPO, Juliana A.; ORLANDO, Jaqueline. Inter-ação, Goiânia, v.41, n.3, p.565-584, 2016. Disponível em: http://dx.doi.org/10.5216/ia.v41i3.41819. Acesso em: 29 jun. 2020.

VERGUEIRO, Waldomiro.; RAMOS,Paulo. Os quadrinhos (oficialmente) na escola: dos PCN ao PNBE. In: VERGUEIRO, Waldomiro.; RAMOS, Paulo (org.). Quadrinhos na Educação: da rejeição à prática. São Paulo: Contexto, 2009. p.6-33.

VERGUEIRO, Waldomiro. Uso de HQs no ensino. In: BARBOSA, Alexandre.; RAMOS, Paulo.; VILELA, Túlio.; RAMA, Ângela.; VERGUEIRO, Waldomiro. (org.). Como usar histórias em quadrinhos em sala de aula. 4ed. São Paulo: Contexto, 2014. p.7-19.

VERGUEIRO, Waldomiro. O panorama das histórias em quadrinhos no Brasil. São Paulo: Peirópolis, 2017.

YIN, Robert K. Pesquisa qualitativa do início ao fim. Porto Alegre: Penso, 2016.

\section{Agradecimentos}

O presente estudo realizado com apoio da Coordenação de Aperfeiçoamento de Pessoal em Nível Superior- Brasil (CAPES)- Código de financiamento 001.

Recebido em: 30/06/2020

Parecer em: 08/07/2020

Aprovado em: 17/09/2020 